\title{
Spondyloepiphyseal Dysplasia Tarda with Progressive Arthropathy Associated with Early-onset Hip Arthritis - A Case Report
}

\author{
C. Prabaharan ', J. K. Giriraj Harshavardhan ${ }^{1}$, P. Gopinath Menon ${ }^{1}$
}

Learning Point of the Article:

Pre-operative planning helped in identifying intraoperative difficulties before surgery+ thorough clinical and radiological evaluation helped in diagnosing rare diseases of SEDT with progressive arthropathy.

\section{Abstract}

Introduction: Spondyloepiphyseal dysplasia tarda with progressive arthropathy (SEDT-PA) is a rare inherited dysfunction with autosomal recessive inheritance. SEDT-PA is also named as progressive pseudorheumatoid arthropathy of childhood as it is associated with multiple joint contractures and arthritis. We report a case of SEDT-PA managed with bilateral stage total hip arthroplasty.

Case Report: A 22-year-old lady presented with severe bilateral hip arthritis. Based on her clinical and radiological features described in this article, she was diagnosed as having SEDT-PA. She was managed with bilateral stage total hip arthroplasty. The pre-operative planning and technical challenges of performing this procedure have been described.

Conclusion: Dysfunctions originally of genetic origin like spondyloepiphyseal dysplasia tarda mimics and is commonly misdiagnosed as juvenile chronic arthritis. These patients have disabling early-onset hip arthritis which requires surgery. Arthroplasty is challenging in these patients because of the low proximal femur offset but good results can be obtained after thorough pre-operative planning to tackle intraoperative difficulties.

Keywords: Spondyloepiphyseal dysplasia, Early-onset hip osteoarthritis, Bilateral total hip arthroplasty.

\section{Introduction}

Spondyloepiphyseal dysplasia tarda with progressive arthropathy (SEDT-PA) is described in the literature as progressive pseudorheumatoid arthropathy of childhood or progressive pseudorheumatoid chondrodysplasia [1]. Many of these patients may be mistakenly diagnosed as having juvenile chronic arthritis for which they may be treated without any relief [11]. Hence, it is important to identify this condition based on the patient's clinical and radiological features to avoid mistreatment.

\section{Case Report}

A 22-year-old intelligent lady presented with complaints of severe bilateral hip joint pain, trouble in walking, and disfigurement in hands, elbow, and spine. Symptoms began first at 6 years of age with pain and stiffness of the fingers.

She was diagnosed as juvenile chronic arthritis outside and managed conservatively with nonsteroidal anti-inflammatory drugs (NSAIDs) and diseases modifying anti-rheumatic drug methotrexate $15 \mathrm{mg} /$ weekly by oral route for the past 2 years till surgery. Her symptoms worsened with age and there was progression of deformities of the fingers, elbow, spine, and hip joint.

Her family members including parents and siblings had no similar symptoms. Family history of short stature and spinal deformation was present in the maternal side, but accurate details were not available about the concerned family members.

On physical examination, she had normal facial features. Her height was only $136 \mathrm{~cm}$; the upper segment (head to pubis 62 $\mathrm{cm}$ ) was smaller than the lower segment (pubis to heel $74 \mathrm{~cm}$ ),

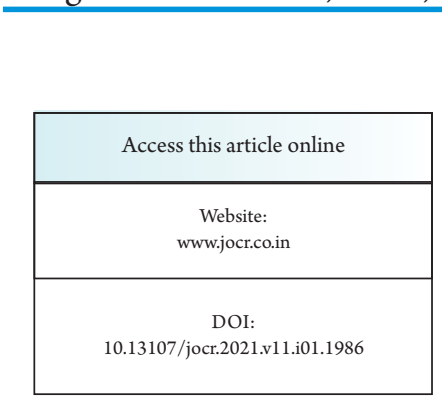

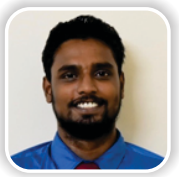

Dr. C. Prabaharan

Author's Photo Gallery

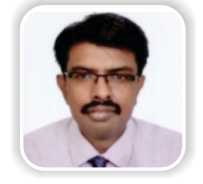

Dr. J. K. Giriraj Harshavardhan

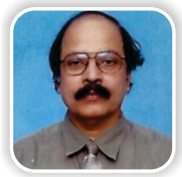

Dr. P. Gopinath Meno

${ }^{1}$ Department of Orthopaedic, Sri Ramachandra Medical College and Research Institute, Chennai, Tamil Nadu, India.

Address of Correspondence:

Dr. C. Prabaharan,

Department of Orthopaedic, Sri Ramachandra Medical College and Research Institute, Chennai - 600 116, Tamil Nadu, India.

E-mail: drpraba2011@gmail.com

Journal of Orthopaedic Case Reports | pISSN 2250-0685 | eISSN 2321-3817 | Available on www.jocr.co.in | doi:10.13107/jocr.2021.v11.i01.1986 This is an Open Access article distributed under the terms of the Creative Commons Attribution Non-Commercial License (http://creativecommons.org/licenses/by-nc/3.0) which permits unrestricted non-commercial use, distribution, and reproduction in any medium, provided the original work is properly cited. 


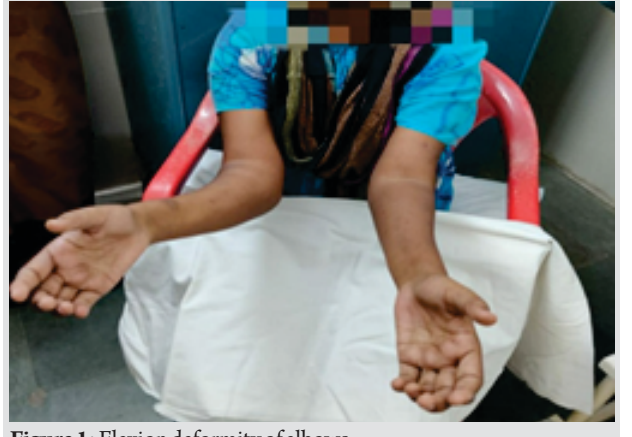

Figure 1: Flexion deformity of elbows

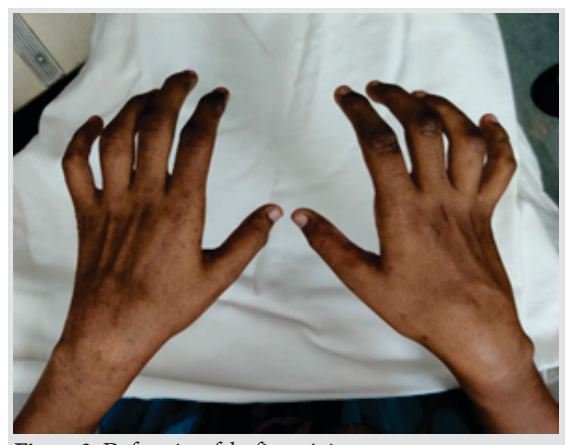

Figure 2: Deformity of the finger joints.

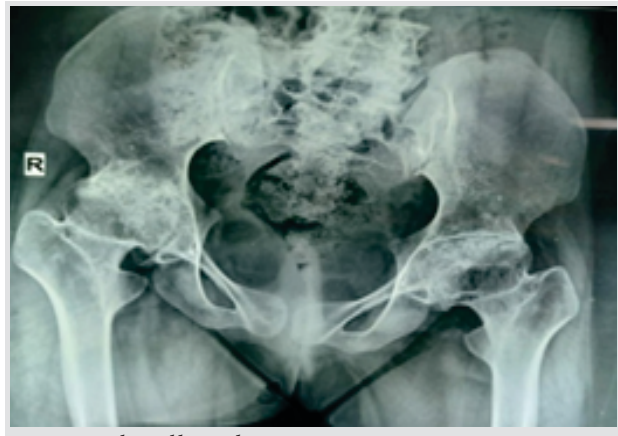

Figure 3: Bilateral hip arthritis. and arm span $(149 \mathrm{~cm})$ was longer than height. She had a mild kyphosis deformity of the thoracic spine and lumbar list present due to hip joint contracture and pelvic tilt. No structural scoliotic deformity seen. There were flexion deformities of the distal interphalangeal joints in the hand and elbow (Figs. 1 and 2) and hallux valgus deformities of the great toes. All movements of both the shoulders and hips were painful and restricted. She had antalgic gait and was confined to bed for the past 3 months due to the increasing hip pain. Measurements of lower limb true length of the right side measured $96 \mathrm{~cm}$ and left about $98 \mathrm{~cm}$. Limb length discrepancy of $1 \mathrm{~cm}$ was present preoperatively. Her Harris hip score at this time was 21 .

Inflammatory markers, including rheumatoid factor, anticyclic citrullinated peptide, and antinuclear antibody, were negative. Her bone mineral profile and thyroid function test were normal.

Anteroposterior X-ray of the hip joint showed severe arthritic changes with a reduction of bilateral femoroacetabular joint spaces (right $>$ left) and subchondral sclerosis (Fig. 3). The femoral neck was short and head mushroom shaped. X-ray of the hands revealed periarticular osteoporosis, a notable narrowing of the joint spaces of proximal interphalangeal and distal interphalangeal joints, and osseous enlargement of the base of the metacarpal, proximal, and distal phalangeal bones (Fig. 4). In the lateral vertebral radiograph of the lumbar spine, there was generalized osteopenia. Platyspondyly and

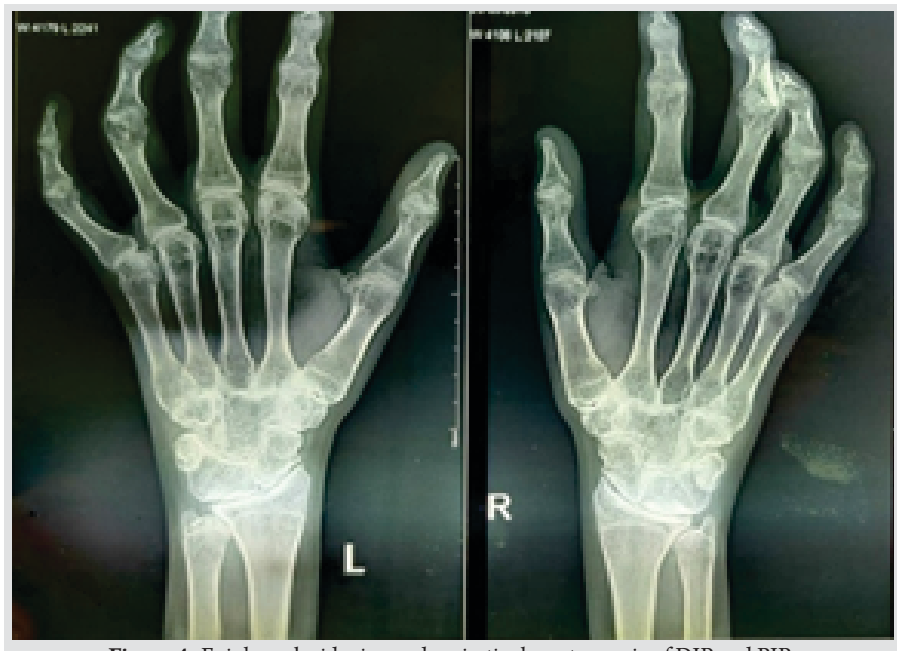

Figure 4: Epiphyseal widening and periarticular osteopenia of DIP and PIP. hyperostosis on the posterior two-thirds of end plates giving rise to a heaped-up or hump-shaped appearance was noted (Fig. 5). Platyspondyly and Schmorl's nodes suggestive of degenerative changes were also noted on the magnetic resonance imaging of the spine (Fig. 6). She was diagnosed as SEDT-PA with Stage IV bilateral hip joint osteoarthritis.

In view of her short stature and reduced vertical and horizontal offset of proximal femur noted on the X-ray, difficulties in performing the total hip replacement were anticipated. The acetabulum could easily be managed as cups of all sizes including small-sized cups are easily available nowadays. However, the low offset proximal femur presented a difficulty as the patient could not afford modular low offset uncemented stems like the Depuy S-ROM stems. The medullary canal of the femur was also very narrow which precluded the use of regular size uncemented tapered stems. Hence, pre-operative templating was done to find out the approximate size of the acetabular cup and distance from the upper border of lesser trochanter to the center of the femoral head which would give an idea of the offset. X-ray of the right hip with a magnification marker (25 mm diameter Rs. 2 coin) was taken (Fig. 7) and the acetabular cup size was measured as $48 \mathrm{~mm}$ and the distance between the upper border of lesser trochanter and center of the femoral head was measured as $30 \mathrm{~mm}$ (usually between 40 and $60 \mathrm{~mm}$ ). Acetabular component size is estimated by drawing a

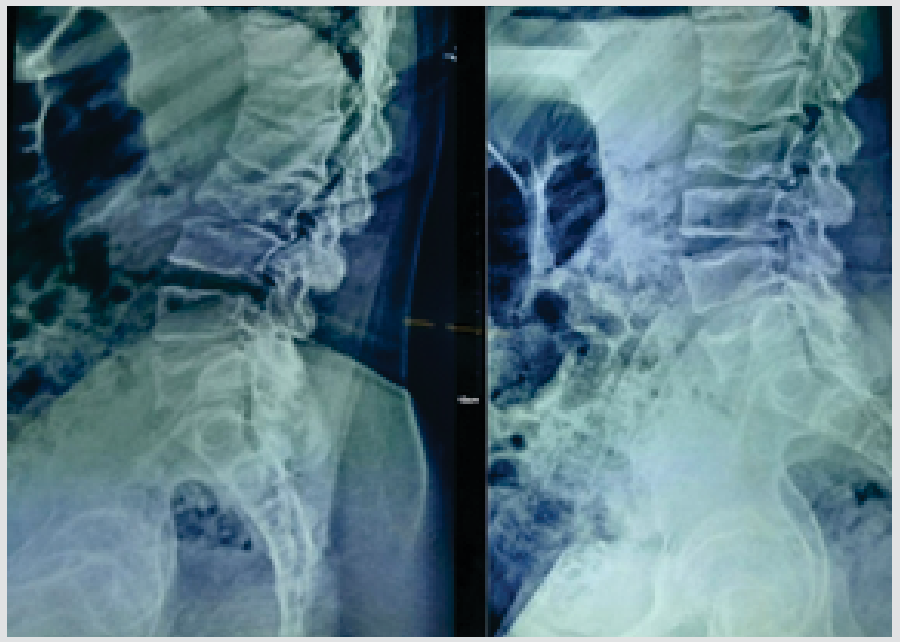

Figure 5: Heap up appearances. 


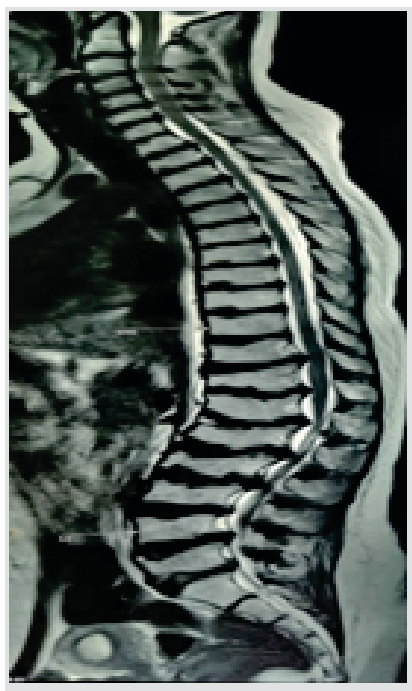

Figure 6: Magnetic resonance imaging of the spine.

line from the inferior wall of a teardrop to the lateral most tip of the acetabulum.

The right hip was exposed by posterolateral approach after a percutaneous adductor tenotomy. We had kept ready the complete array of uncemented and cemented acetabular cups and femoral stems from Depuy (including $\mathrm{CDH}$ stem). Due to logistic reasons, SROM femoral stem could not be arranged. Acetabulum was reamed up to $44 \mathrm{~mm}$. Size $44 \mathrm{~mm}$ Pinnacle uncemented cup was inserted with good fit in $40^{\circ}$ of inclination and $20^{\circ}$ of anteversion (additional two screws were also used). Preparation of the femoral canal for an uncemented stem was initially done. However, reduction of the prosthesis could not be achieved even with the smallest size uncemented stem in view of patient's reduced native vertical offset. Hence, a size 1 cemented $\mathrm{C}$ stem with $9 / 10$ taper was cemented ensuring that the distance between the upper border of the lesser trochanter and the proximal end of the neck of the prosthesis (neck length) was $30 \mathrm{~mm}$ as preoperatively templated. Minus $3 / 28 \mathrm{~mm}$ head was used. Prosthesis was reduced with good stability and adequate range of motion. Hybrid total hip arthroplasty of the left hip was done 8 months later following a similar technique with $46 \mathrm{~mm}$ pinnacle cup fixed with one screw, head and cemented stem of same size as the right side was used.

\section{Discussion}

SEDT-PA is an uncommon inherited ailment also called pseudorheumatoid dysplasia of childhood because of small joint involvement with progressive flexion deformation of fingers of the hand $[6,7]$. It is characterized by cardinal features a pattern of autosomal recessive inheritance [2], the onset of symptoms at about age between 3 and 8 years, the involvement of the spine and epiphyses of bones, leading subsequently to disproportionate short stature; thoracic kyphoscoliosis; and pain, swelling, stiffness, and contracture about multiple articulations most commonly in the joints of hands, hips, elbows, and feet, normal values of the routine laboratory studies, notable disability in childhood caused by the early degenerative changes in the spine and hip joints, and a lack of response to antirheumatic drugs [4]. SEDTPA is generally misdiagnosed as juvenile idiopathic arthritis which leads to unnecessary medication with NSAIDs and disease-modifying antirheumatic drugs. Longer arm span, short stature, and disproportionate growth of the upper and lower segment are

Table 1: Characteristics of patients diagnostic

\begin{tabular}{|c|c|c|}
\hline Components & Formula used & Patient size \\
\hline \multirow[t]{2}{*}{ Acetabular component size (a) } & $\mathrm{a}=$ Size of acetabulum measured on X-ray & $44 \mathrm{~mm} \times 25 \mathrm{~mm} / 23 \mathrm{~mm}=48 \mathrm{~mm}$ \\
\hline & $\begin{array}{l}\mathrm{x} \text { actual diameter of coin/Diameter of coin } \\
\text { measured on X-ray }\end{array}$ & \\
\hline Neck length (b) & $\begin{array}{c}\mathrm{b}=\text { Distance from upper border of lesser } \\
\text { trochanter to center of neck measured on X- } \\
\text { ray } \mathrm{x} \text { true diameter of coin/diameter of coin } \\
\text { measured on X-ray }\end{array}$ & $28 \mathrm{~mm} \times 25 \mathrm{~mm} / 23 \mathrm{~mm}=30 \mathrm{~mm}$ \\
\hline
\end{tabular}

Journal of Orthopaedic Case Reports | Volume 11 | Issue 1 | January 2021 | Page 113-117 
known features of the SEDT. Our patient's height was $139 \mathrm{~cm}$ and the arm span was $147 \mathrm{~cm}$. Her arm span is longer than his height and the upper segment (vertex to pubis) was shorter than lower segment (pubis to the floor) like other patients. Platyspondyly with heaping up and hyperostosis on the posterior two-thirds of end plates giving rise to a heaped-up or hump-shaped appearance is the classical X-ray appearance of SEDT [5]. Because of platyspondyly with short stature, longarm span, and disproportionate length difference between upper and lower segment, progressive fixed flexion deformity of fingers and elbows, she was recognized as SEDT-PA. It is harmonious with autosomal recessive inheritance because no other family members, brothers, or sisters are affected. As per history, there is skip in generations which is also compatible with autosomal recessive inheritance.

In view of her short stature, pre-operative planning helped in identifying intraoperative difficulties before surgery $[8,9,10]$. In this case, the smaller vertical offset was identified preoperatively and hence we were ready with a cemented femoral component which was used to reduce the offset (Table 1). The other option would have been using a modular uncemented stem like the SROM system which could not be make available. There was no difficulty in managing the acetabular component.

The patient had excellent relief of pain and she managed to walk without support just 2 months after the left-sided procedure.
There is no limb length discrepancy postoperatively. She returned to her office job and is able to manage her daily activities well. Her Harris hip score improved to 81 even at the 4 months follow-up after the second left side arthroplasty.

\section{Conclusion}

Dysfunctions originally of genetic origin like spondyloepiphyseal dysplasia tarda mimics and is commonly misdiagnosed as juvenile chronic arthritis. These patients have disabling early-onset hip arthritis which requires surgery. Arthroplasty is challenging in these patients because of the low proximal femur offset but good results can be obtained after thorough pre-operative planning to tackle intraoperative difficulties.

\section{Clinical Message}

Clinical finding of arm span greater than height is classical for diagnosis of SDET-PA. Radiologically "heap up appearance" of vertebral body is diagnostic of SDET. Arthroplasty is challenging in these patients because of the low proximal femur offset but good results can be obtained after thorough pre-operative planning to tackle intraoperative difficulties.

\section{References}

1. Wynne-Davies R, Hall C, Ansell BM. Spondylo-epiphysial dysplasia tarda with progressive arthropathy. A "new" disorder of autosomal recessive inheritance. J Bone Joint Surg Br 1982;64:442-5.

2. Warman ML, Cormier-Daire V, Hall C, Krakow D, Lachman R, LeMerrer M, et al. Nosology and classification of genetic skeletal disorders: 2010 revision. Am J Med Genet A 2011;155:943-68.

3. McAlister WH, Resnick D, Niwayama G. Osteochondrodysplasias and other skeletal dysplasias. In: Diagnosis of Bone and Joint Disorders. Philadelphia, PA: W.B. Saunders; 1988.p. 3442-515.

4. Bal S, Kocyigit H, Turan Y, Gurgan A, Bayram KB, Güvenc A, et al. Spondyloepiphyseal dysplasia tarda: Four cases from two families. Rheumatol Int 2009;29:699-702.

5. Panda A, Gamanagatti S, Jana M, Gupta AK. Skeletal dysplasias: A radiographic approach and review of common non-lethal skeletal dysplasias. World J Radiol 2014;6:808-25.

6. Spranger J, Albert C, Schilling F, Bartsocas C, Stöss H.
Progressive pseudorheumatoid arthritis of childhood (PPAC). A hereditary disorder simulating rheumatoid arthritis. EurJ Pediatr 1983;140:34-40.

7. Arslanoğlu S, Murat H, Ferah G. Spondyloepiphyseal dysplasia tarda with progressive arthropathy: An important form of osteodysplasia in the differential diagnosis of juvenile rheumatoid arthritis. Pediatr Int 2000;42:561-3.

8. Conn KS, Clarke MT, Hallett JP. A simple guide to determine the magnification of radiographs and to improve the accuracy of preoperative templating. J Bone Joint Surg Br 2002;84:269-72.

9. Della Valle AG, Slullitel G, Piccaluga F, Salvati EA. The precision and usefulness of preoperative planning for cemented and hybrid primary total hip arthroplasty. J Arthroplasty 2005;20:51-8.

10. Eggli S, Pisan M, Müller ME. The value of preoperative planning for total hip arthroplasty. J Bone Joint Surg Br 1998;80:382-90.

11. Yurdakul FG, Kocak R, Sivas F, Güvenir AA, Bodur H. 
Spondyloepiphyseal dysplasia tarda with progressive arthropathy associated with osteoporosis and cataract: A case was misdiagnosed as juvenile idiopathic arthritis. Clin Med Rev Case Rep 2015;2:62.

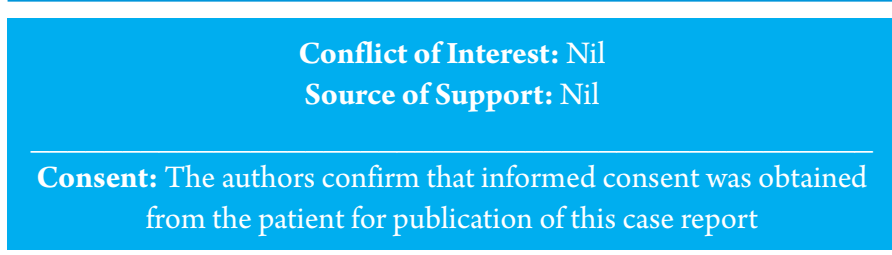

\section{How to Cite this Article}

Prabaharan C, Harshavardhan JK, Menon PG. Spondyloepiphyseal Dysplasia Tarda with Progressive Arthropathy Associated with Early-onset Hip Arthritis - A Case Report. Journal of Orthopaedic Case Reports 2021 January;11(1): 113-117. 